\title{
THE AESTHETIC AND PLASTIC CAPABILITIES OF THE ART OF MACRAMÉ AND UTILIZING IT IN DESIGN AND IMPLEMENTATION WOMEN'S CLOTHING SUPPLEMENT
} Mona Ezzat Hamid ABDEL AZIZ ${ }^{1, *}$, Rasha Hassan Hosni SALEM ${ }^{2}$

${ }^{1}$ Department of Garments and Textiles, Faculty of Home Economics, Helwan University, Egypt

${ }^{2}$ Department of Home Economics, College of Management and Home Economics, King Khalid University, Saudi Arabia

\begin{abstract}
The art of Makramia is one of the fine handicrafts that people have been interested in until recently. It is also a very old art and has differed in determining its source, is it from the ancient Egyptian or Phoenician civilization or it came recently by the Arab civilization, and most modern references mention that the word Makramia is Arabic The origin and meaning of severe twisting of ropes, which is derived from "openwork," and it is mentioned in the Oxford dictionary that the word "macrame" or makrami or makrama or magrama is used in the Turkish civilization for some furnishings, napkins and towels, and the word macrame is used in the references on the works of the contract and it is known that the artist The Egyptian folklore used to produce many forms of macramé, especially used in Egyptian decor, and the most distinguished of them are pendants to hang flowers or mirrors, and this art continued in circulation for long periods of time until its use decreased clearly despite the aesthetics of the art of macramé, as well as the possibility of change and formation in its products and in its stitches.

Keywords

The Aesthetic, Plastic, The Art Of Macramé, Design, Women's Clothing.
\end{abstract}

\section{Introduction}

since clothing supplements are from the plastic arts in which the individual creates and creates using raw materials and tools what he likes, in order to achieve in the end a useful artistic work in which aesthetic relations are confirmed and that Its basis is line, shape, area, mass, texture, color, and surface section, due to the influence of clothing supplements by modern artistic trends in terms of shape, styles and technology with an awareness of the material as new materials were introduced that had a great impact on creativity in this field (Dalia Fawzy 1998) The material is what raises in the artist psychological and mental states that help him reproduce his ideas, due to their nature and the state on them, and special plastic procedures are imposed on him commensurate with the formulation of the form in the style and emotion to be achieved in the work, so the materials are material media that help the artist to achieve his ideas based on the characteristics Affecting the shaping methods, which is what prompted the researcher to try to take advantage of macramé materials and methods of shaping in the design and implementation of women's clothing supplements.

There are many natural and industrial materials that are used in the manufacture of clothing supplements, as the materials used work to stimulate the artist's imagination and make him

* Corresponding author: homeecon@helwan.edu.eg 
enter into a mutual and permanent struggle with it, and through it he uses various plastic skills as it helps him to create new works of art and this leads to the artist's interaction with the material and given that The modern trend in the field of clothing design requires the innovation of new and strange shapes and different types of clothing supplements, which has been shown by the results of many studies and research in the field of clothing supplements such as the study (Nadia Mahmoud Khalil - 1998 AD) which dealt with the study of the scientific and technical foundations of adjacent to the remnants of fabrics in the implementation of supplements Productive families 'clothes, so I prepared a program for this to design and implement clothing supplements using the remnants of fabrics, helping trainers and supervisors to manage productive families so that they could teach girls who had been trained in productive families' centers, and a 1999 study that focused on an analytical study of folk motifs in Siwa Oasis through several aspects of formation methods - Formation - symbolism - technology, and obtaining innovative models of clothing supplements and crafts An artistic life

Modern The results that the researcher implemented by absorbing the many artistic values of this heritage and formulating them with an updated vision commensurate with the contemporary use of tourist crafts and clothing supplements. The results also showed the compatibility of materials and their characteristics with the functional values of clothing supplements and tourist crafts in terms of size, texture and methods of implementation, and a study that aimed To designing an educational unit to develop students' creative skills in creating new technical treatments such as recycling raw materials and employing them in clothing supplements, and trying to link curricula with changes in society and the future outlook and needs of students in order to face the challenges of the age and contemporary global changes, while opening the way for students to get acquainted with On their creativity and expressing them in the field of artistic applications, coming up with recommendations and proposals that may help to activate the use and development of different strategies and learning methods in educational institutions, and a study that included studying some decorative elements woven and embroidered from the ancient Egyptian heritage and employing them in contemporary decorative designs for clothing supplements, as well as studying My style of decoration Textile and embroidery and benefiting from them in the field of clothing supplements and highlighting the two styles of textile decoration and embroidery in implementing clothing supplements characterized by both aesthetic and functional values, with the aim of reviving the artistic heritage of some ancient Egyptian decoration methods. One of the results of the study is the possibility of employing decorative textile pieces, whether by weaving or embroidery in the style of non-extended weft And simple tissue compositions 
And the characteristics of the materials used in the implementation in making clothing supplements, so the two researchers conducted this study in an attempt to benefit from some of the canvas stitches in a contemporary artistic and applied way in the design and implementation of some clothing supplements. Despite the diversity of studies that dealt with the design and implementation of garment supplements, none of these studies did not address the art of macrame in the design and implementation of women's clothing supplements, hence the idea of research, as the researchers found in the art of macrame as a fertile source that can be used in the design and implementation of women's clothing supplements.

\section{Research problem :-}

\section{The research problem is summarized in the following questions:}

1. To what extent can the art of macramé be used to create unique and varied designs for women's clothing accessories?

2. What is the opinion of the specialists about the designs executed in terms of aesthetics and functionality?

3. What is the degree of consumer acceptance of the implemented designs?

\section{Theoretical framework :}

The art of making macramé is one of the international arts in which plant fibers or strings are used. This art is called Arabic lace or decorative complexity. Interior designers have invested this art in many fields in decorating homes through the use of knot technique and the aesthetics of the implementation of macrame art. They are innovative arts and crafts that provide creative abilities that can be employed in the implementation of this art of handicrafts using ropes, beads, crystal, palm leaves and plasticine, and the origin of the name is from the Turkish word "Makrama", which means the veil or the khimar, or the towel with knotted tassels, It is the art of knitting strings and ropes in an artistic way that gives them an aesthetic appearance. Macrame is used in curtains, bags, necklaces and lampshades. This art depends on the manufacturer's counting of units or arguments. Man has created an endless series of knots that are useful for all purposes, the most important of which are tying, fixing, hanging and knots. Many shapes, and the art of macramé needs soft, durable threads so that it does not break off during work and that the threads are good to spin

It is also possible to use other materials such as plastic, beads and butterflies, ribbons, wires, bobbins, wooden rings and various metal shapes, so that at the end of the work, an artistic formation that is characterized by consistency and innovation for these works and craft is the best economically viable thread. It was generated when a person needed to connect or combine two ropes with strength and stability, so the square knot and the midline knot appeared, and 
these knots were used when sailors used them in making fishing nets. Knots were also used as splints for fractures as well as knots in ropes to help them know accounts and other information. Knots were also indicative of some religious beliefs and magic, and were used in clothes and collectibles. With the passage of time, this craft developed and reached the level of art and creativity, and every person began to be distinguished in a certain style by using the basics of macramé, which are (strings, square knots and half knots) and the appearance of macramé may seem as if it is very difficult and complex, but only two knots are used in its work, and these knots can be doubled. To reach the desired final shape

\section{Macramé Shaping Methods:}

The basis in the formation of the art of macramé is the knots, which is the intertwining of the ends of a rope or string, and man has created an endless chain of knots that are useful for all purposes, the most important of which are tying, fastening and hanging

\section{Raw materials used:}

\section{Types of threads:}

Cotton, linen, silk or wool threads are used, and linen threads are considered the best viable yarns from the economic ones due to their durability and durability.

\section{Yarn qualities:}

The art of macramé needs to be smooth, durable threads so that it does not break, and the yarns must be well-spinning, full-round, so that certain knots can be obtained through which we reach waves of knots confirming the aesthetics of the decoration, and the thickness of the threads used depends on the functional purpose of the design being executed

\section{Added costs:}

Nylon strings, metallic strings, wires, beads, ribbons, wooden rings, various metal shapes can be added to create a consistent and innovative artwork.

\section{Types of contract:}

Macramé is based on two main nodes that are formed on the basis of their succession and repetition, namely:

- Half node

- Square knot

- Half node

- Square knot

\section{Materials:}


- Red and brown colored silk threads

- Metal wire to form an earring ring

- Mild glue to make strands shine and strengthen

\section{Execution method:}

1. Divide the colored strings into lengths commensurate with the design implemented

2. The half knot stitch was used

3. Painting with diluted glue after the finished piece is finished

Fifth design

\section{Design seven and eight:}

Ores:

- Purple and black colored silk threads

- Metal wire to form an earring ring

- Mild glue to make strands shine and strengthen

\section{Execution method:}

1. Divide the colored strings into lengths commensurate with the design implemented

2. The half knot stitch was used

3. Painting with diluted glue after the finished piece is finished

Seventh design

Ninth design:

Extension type: belt strap

Ores:

- Red and green colored silk threads

- $\quad$ Red and green wooden beads

- Mild glue to make strands shine and strengthen

\section{Execution method:}

1. Divide the colored strings into lengths commensurate with the design implemented

2. The half knot stitch was used

3. Painting with diluted glue after the finished piece is finished

Ninth design

Tenth design:

Complementary type: necklace

Ores:

- Red and purple colored silk threads 
- Red glass beads

- Mild glue to make strands shine and strengthen

\section{Execution method:}

1. Divide the colored strings into lengths commensurate with the design implemented

2. The half knot stitch was used

3. Painting with diluted glue after the finished piece is finished

Tenth design

\section{Eleventh design:}

Complementary type: necklace

\section{Ores:}

- Red and green colored silk threads

- Najaf came out green plastic

- Mild glue to make strands shine and strengthen

\section{Execution method:}

1. Divide the colored strings into lengths commensurate with the design implemented

2. The half knot stitch was used

3. Painting with diluted glue after the finished piece is finished

Design XI

\section{The second section of the results:}

\section{Survey results:}

\section{The first assumption:}

There are differences between the designs in achieving the design elements according to the opinions of specialists. To verify this hypothesis, the analysis of variance was calculated for the average degrees of designs in achieving the principles of design.

Differences between designs in achieving the principles of design according to the opinions of specialists and knowing the direction of significance.

Clarifies the differences between design degrees in achieving the foundations of design according to professional opinion

From the previous figure it becomes clear that the indicative trend in the differences between the designs tends in favor of the fifth design, followed by the seventh design, then the fourth and eighth design.

\section{The second assumption:}

There are differences between the designs in achieving the aesthetic aspect according to the 
opinions of specialists and to verify this hypothesis, the analysis of variance was calculated for the average degrees of designs in achieving the aesthetic aspect. Analysis of variance of the average degrees of designs in achieving the aesthetic aspect according to the opinions of design specialists.The extent to which the aesthetic aspect is achieved. From the previous table, the value of $(\mathrm{P})$ was (7.689), which is a statistically significant value at the level of 0.000 , which indicates the existence of differences between the designs in achieving the aesthetic aspect according to the opinions of specialists.

It clarifies the differences between the degrees of designs in achieving the aesthetic aspect according to the opinions of specialists from the previous figure. It is clear that the direction of significance in the differences between the designs tends in favor of the eighth design, followed by the sixth design, then the fifth and the third, and the designs that achieve the least aesthetic aspect are the tenth and ninth, respectively, according to the opinions of the arbitrators.

\section{The third hypothesis:}

There are differences between the designs in achieving the functional aspect according to the opinions of specialists, and to verify this hypothesis, the analysis of variance was calculated for the average degrees of designs in achieving the functional aspect.

Analysis of variance of the average degrees of designs in achieving design elements according to the opinions of design specialists

Differences between designs in achieving the functional aspect according to the opinions of specialists and knowing the direction of significance, clarifying the differences between the degrees of designs in achieving the functional aspect according to the opinions of specialists From the previous figure, it becomes clear that the indicative trend in the differences between the designs tends in favor of the sixth design, followed by the fifth design, then the eighth and the first, and the designs that achieve the least functional aspect are the eleventh and tenth, respectively, according to the opinions of the arbitrators.

\section{The fourth assignment:}

The designs achieve a degree of acceptance and success in light of the average rating of consumers. To verify this hypothesis, the analysis of variance was calculated for the average score of designs in achieving the degree of consumer acceptance of designs. The design is the extent to which the degree of consumer acceptance is achieved. Average variance analysis Standard deviation of significance.

As for the first question, which states, "To what extent can the art of macramé be used to create unique and varied designs for women's clothing supplements?" The results indicated that it is possible to benefit from the plastic capabilities of the art of macramé in the field of 
clothing supplements with modern configurations, designs and methods of implementation that can be achieved from During which diversity, innovation and innovation.

As for the second question, which states, "What is the opinion of the specialists in the designs executed in terms of aesthetics and functionality?" And also the third question which states, "What is the degree of consumer acceptance of the designs implemented?" And these questions were answered by presenting the first section of the research results, represented in the designs carried out, the number of designs on the research sample and their number for polling their opinions. The sample divided into two parts, which are specialists in the field and their number, and female consumers and their number, who were classified according to the economic level and the approximate proportion of spending on supplements, age and level of education. The results of the two questionnaires were presented and tabulated to answer the second and third questions.

\section{Recommendations:}

1. Interest in developing new methods inspired by the plastic arts capabilities of different arts, and employing them for preparing clothing supplements.

2. Unleash the innovative ideas that are generated at the lowest possible costs.

3. The possibility of using the existing designs in the research and employing them as a small project due to the simplicity of the tools used and their low cost.

4. Inclusion of the art of macramé as an educational unit in the clothing supplement course.

\section{References:}

1. The congratulations of Muhammad Abu Al-Anwar: The possibility of benefiting from the Egyptian nationalist motifs in enriching the aesthetic values of the complements. The possibility of using the designs found in research and employing them as a small project for the simplicity of the tools used and their cost in order to eliminate unemployment.

2. Hanan Hassan, Imanbhansi: Reviving the art of Makramia as one of the ancient Egyptian folk crafts and making use of it to enrich the aesthetic value of used clothes - Science and Arts Magazine - Studies and Research Egypt - Vol. 24 - Issue 2 - April 2012

3. Hanan Abd Al-Nabi Al-Sayed: Needle arts and the possibility of benefiting from it in the work of any supplements - Master's thesis - Faculty of Home Economics - University of Menoufia - 2004 AD

4. Dalia Faouzi Abdullah: Inspiration of Surrealist Concepts as an Entrance to Creating Decorations Supplements - A Master's Thesis from a publication - Faculty of Art Education University of Helwan 
5. Samia Al-Sayed Aliouh: A proposed program to develop methods of designing clothing supplements using the computer - a master's thesis not published - Department of Clothes and Textile - Faculty of Home Economics - Helwan University 2007 A.D. 1497 A.D.

6. Sherif Mohamed Youssef Ahmed: Benefiting from the mentality of the remnants of leather and jeans fabrics in designing some clothing supplements - a master's thesis not published Department of Clothes and Textiles - Faculty of Home Economics - University of Menoufia $2005 \mathrm{AD}$

7. Al-Shaimaa Masaad Muhammad Ibrahim: A study of complementaries to the adornment of women depends on the synthesis of materials and benefit from the methodology of creating a design inspired by popular geometric shapes - a master's thesis not published - Faculty of Quality Education - Ain Shams University 2006

8. Abira Ibrahim, Karamah Thabit: A proposed educational unit to develop the creative skills of female students in the development of new technical treatments from the recycling of raw materials and their employment in clothing supplements - Journal of Quality Education Mansoura University - Volume 25 - Issue 25 - 2012

9. Lamia Ibrahim Ahmed Abdel Fattah: Training program to qualify female graduates to manufacture some clothing supplements, remnants of fabrics - the second annual Arab Fifth International Conference "Modern trends in the development of institutional and academic performance in higher education institutions in the Arab world in the period 15-14 April 2010 10. Muhyiddin Al-Talw: Traditional Handicrafts for Amateurs - Part Two of The Creative Hand - Dardamashqal Publishing and Distribution - First Edition

11. Marwa Ibrahim Mahmoud: An Analytical Study of Some of the Contents of the Environment and Their Possibility of Employment in the Field of Clothes and Their Supplements - Master's Thesis - Faculty of Home Economics - University of Menoufia 2006 12. Mona Ahmed Youssef: a plastic vision for popular decorations and their symbolic connotations and the use of them in the field of clothing and their accessories - Master's Thesis - Faculty of Home Economics - Helwan University - 2006

13. Nadia Mahmoud Khalil A study of the scientific and technical foundations of adjacent to the remnants of fabrics in the implementation of supplementary clothes for productive families, the third Egyptian Conference for Home Economics - Issue 3 - Volume 4 - Faculty of Home Economics, Menoufia University - 1998 AD

14. Clothes, Accessories, Accessories, Elegance and Beauty - Dar Al Fikr Al Arabi - First Edition - 1999 AD .

15. Amal Gerges William HABIB, Zainab Abdel Hafeez FARGHALI, Magda Youssef 
THE AESTHETIC AND PLASTIC CAPABILITIES OF THE ART OF MACRAMÉ AND UTILIZING IT IN DESIGN AND IMPLEMENTATION WOMEN'S CLOTHING SUPPLEMENT

MOHAMED, PROBLEMS OF LASER CUTTING IN THE READY MADE GARMENT, International Journal of Design and Fashion Studies, Vol. 2, No. 1, 2019, pp. 12-17.

16. Ashraf Mustafa Ali LABIB, SPACE- SAVING AND MULTIPLE USING FURNITURE, International Journal of Design and Fashion Studies, Vol. 2, No. 1, 2019, pp. 18-21.

Received: September 4, 2019

Accepted: November 21, 2019 